\title{
Chronic kidney disease in urolithiasis patients following successful extracorporeal shockwave lithotripsy
}

\author{
SATOSHI MAEDA $^{1}$, TOSHIHIDE NAGANUMA $^{1}$, YOSHIAKI TAKEMOTO ${ }^{1}$, \\ TETSUO SHOJI $^{2}$, MIKIO OKAMURA ${ }^{3}$ and TATSUYA NAKATANI ${ }^{1}$ \\ Departments of ${ }^{1}$ Urology and ${ }^{2}$ Endocrinology, Metabolism and Molecular Medicine, Osaka City University \\ Graduate School of Medicine; ${ }^{3}$ Department of Nephrology, Ohno Memorial Hospital, Osaka, Japan
}

Received May 5, 2011; Accepted August 17, 2011

DOI: $10.3892 / \mathrm{mmr} .2011 .586$

\begin{abstract}
Recently, it has been reported that kidney stones are a significant and independent risk factor for chronic kidney disease (CKD) in the general population. However, the prevalence of CKD in patients following successful extracorporeal shockwave lithotripsy (ESWL) has yet to be elucidated. In the present study, the prevalence of CKD and the clinical factors associated with the presence of CKD in patients following successful ESWL were investigated. A cross-sectional study was performed in 114 patients who had undergone ESWL for upper urinary tract stones and 96 age- and gender-matched healthy control subjects. We initially determined the stage of CKD and compared the prevalence of CKD between healthy subjects and patients who underwent successful ESWL. We then investigated the clinical factors associated with the presence of CKD by logistic regression analysis. The prevalence of CKD was significantly higher in patients following successful ESWL than in the healthy subjects [40 patients $(35.1 \%)$ vs. 9 healthy controls (9.4\%), $\mathrm{P}<0.0001]$. Logistic regression analysis showed that the significant factors associated with the presence of CKD were increased body mass index (BMI) and the presence of a ureteric stone (pre-ESWL stone position). The findings indicated that there was a high prevalence of CKD among patients following successful ESWL, and that an increased BMI and a ureteric stone were factors associated with the presence of CKD.
\end{abstract}

\section{Introduction}

Chronic kidney disease (CKD) is a common disease in the elderly population, and its management is a major public health issue in order to prevent renal failure and cardiovascular disease (1-4). Urolithiasis is an equally highly prevalent

Correspondence to: Dr Toshihide Naganuma, Department of Urology, Osaka City University Medical School, 1-4-3 Asahi-machi, Abeno-ku, Osaka, 545-8585, Japan

E-mail: spxd48k9@aria.ocn.ne.jp

Key words: chronic kidney disease, extracorporeal shockwave lithotripsy, urolithiasis disorder, affecting approximately $10 \%$ of the population in Western countries (5-6) and Japan (7), and renal dysfunction is a well-described complication of urolithiasis (8-13). Struvite stones, including staghorn calculi and severe stone disease caused by genetic disorders (e.g., primary hyperoxaluria, cystinuria, Dent disease and 2-8-hydroxyadenine crystalluria) (8-10), are universally considered the most frequent causes of urolithiasis-associated end-stage renal disease (ESRD). On the other hand, it is thought that the more common calcium oxalate or uric acid stones are a painful, but otherwise benign condition, infrequently leading to ESRD. However, it has been reported that renal function is further decreased in adults with kidney stones prior to treatment (11) and those with a history of kidney stones (12) compared to those without. Moreover, it has been reported that kidney stones are a significant and independent risk factor for CKD in the general population (14-16). Since few studies have investigated the prevalence of CKD and the factors associated with the presence of CKD in urolithiasis patients following successful extracorporeal shockwave lithotripsy (ESWL), a cross-sectional study on CKD in these patients was performed.

\section{Materials and methods}

Patients. The subjects were selected from the 134 patients who had undergone ESWL for upper urinary tract stones at Osaka City University Hospital, Japan, between April 2008 and March 2009. The study protocol was approved by the ethics committee of Osaka City University School of Medicine (No. 1496). Informed consent was obtained from all subjects prior to their participation in the study. Of the 134 patients, 20 patients were excluded due to the following exclusion criteria: severe urinary tract infection, chronic glomerulonephritis, chronic inflammatory disease, malignant disease, cystinuria, staghorn calculi, obstructive uropathy (hydronephrosis and/or hydroureter) or double pigtail stent. The remaining 114 patients (following successful ESWL) were studied. Table I shows the characteristics of the 114 patients. The 96 age- and gender-matched healthy subjects who visited Ohno Memorial Hospital regularly for complete physical examinations between April 2008 and March 2009 served as the control group. 
Table I. Characteristics of the urolithiasis patients following successful ESWL with and without CKD, and healthy subjects.

\begin{tabular}{|c|c|c|c|c|c|}
\hline & Total $(n=114)$ & Without CKD $(n=74)$ & With CKD $(n=40)$ & P-value ${ }^{b}$ & $\begin{array}{c}\text { Healthy subjects } \\
(\mathrm{n}=96)\end{array}$ \\
\hline Age (years) & $58.4 \pm 14.1$ & $54.9 \pm 14.6$ & $65.0 \pm 10.8$ & 0.0002 & $57.4 \pm 13.5$ \\
\hline $\begin{array}{l}\text { Gender (males) } \\
\mathrm{n}(\%)\end{array}$ & $75(65.8 \%)$ & $43(58.1 \%)$ & $32(80.0 \%)$ & 0.0320 & $61(63.5 \%)$ \\
\hline Hypertension, n (\%) & $42(36.8 \%)$ & $21(28.4 \%)$ & $21(52.5 \%)$ & 0.0190 & $23(24.0 \%)$ \\
\hline $\begin{array}{l}\text { Diabetes mellitus } \\
\mathrm{n}(\%)\end{array}$ & $31(27.2 \%)$ & $20(27.0 \%)$ & $11(27.5 \%)$ & NS & $8(8.3 \%)$ \\
\hline Dyslipidemia, n (\%) & $31(27.2 \%)$ & $21(28.4 \%)$ & $10(25.0 \%)$ & NS & $29(30.2 \%)$ \\
\hline $\begin{array}{l}\text { Cardiovascular disease } \\
\mathrm{n}(\%)\end{array}$ & $17(14.9 \%)$ & $9(12.2 \%)$ & $8(20.0 \%)$ & NS & $8(8.3 \%)$ \\
\hline $\begin{array}{l}\text { Body mass index } \\
\left(\mathrm{kg} / \mathrm{m}^{2}\right)\end{array}$ & $24.2 \pm 4.2$ & $23.6 \pm 3.7$ & $25.3 \pm 4.8$ & 0.0328 & $23.2 \pm 3.6$ \\
\hline $\begin{array}{l}\text { Stone position } \\
\text { (ureteric stone) } \mathrm{n}(\%)\end{array}$ & $60(52.6 \%)$ & $33(44.6 \%)$ & $27(67.5 \%)$ & 0.0323 & - \\
\hline $\begin{array}{l}\text { ESWL sessions } \\
\text { (multiple) n (\%) }\end{array}$ & $57(50.0 \%)$ & $36(48.6 \%)$ & $21(52.5 \%)$ & NS & - \\
\hline Stone size $(\geq 10 \mathrm{~mm})$ & $74(50.0 \%)$ & $50(48.6 \%)$ & $24(60.0 \%)$ & NS & - \\
\hline $\mathrm{eGFR}\left(\mathrm{ml} / \mathrm{min} / 1.73 \mathrm{~m}^{2}\right)$ & $69.6 \pm 26.6$ & $82.4 \pm 22.1$ & $45.9 \pm 15.6$ & $<0.0001$ & $91.0 \pm 25.1$ \\
\hline Proteinuria, n (\%) & $2(1.8 \%)$ & $0(0 \%)$ & $2(5.0 \%)$ & NS & $0(0 \%)$ \\
\hline CKD, n (\%) & $40(35.1 \%)$ & - & - & - & $9(9.4 \%)$ \\
\hline
\end{tabular}

CKD, chronic kidney disease; BMI, body mass index; eGFR, estimated glomerular filtration rate; ESWL, extracorporeal shockwave lithotripsy. aplus-minus values are the mean $\pm \mathrm{SD},{ }^{b}$ without CKD versus with CKD. NS, not significant.

Definition of chronic kidney disease. In all patients, serum creatinine levels were measured during follow-up (postESWL), and the serum creatinine concentrations obtained at their last visit (mean time from last ESWL; 15.4 \pm 6.7 months) were entered for statistical analysis. The estimated glomerular filtration rate (eGFR) was calculated using the equation of the Japanese Society of Nephrology, as follows: 194 x (age)-0.287 x (serum creatinine)-1.094, including a correction factor of 0.739 for women (17). The patients were stratified into 5 stages based upon their eGFR values: $\geq 90 \mathrm{ml} / \mathrm{min} / 1.73 \mathrm{~m}^{2}$ (Stage 1), 60-89 $\mathrm{ml} / \mathrm{min} / 1.73 \mathrm{~m}^{2}$ (Stage 2), 30-59 $\mathrm{ml} / \mathrm{min} / 1.73 \mathrm{~m}^{2}$ (Stage 3), $15-29 \mathrm{ml} / \mathrm{min} / 1.73 \mathrm{~m}^{2}$ (Stage 4) and $<15 \mathrm{ml} / \mathrm{min} /$ $1.73 \mathrm{~m}^{2}$ (Stage 5), according to the National Kidney Foundation Kidney Disease Outcomes Quality Initiative (NKF-KDOQI) classification and staging system (18). In the present study, CKD was primarily defined as an eGFR of $<60 \mathrm{ml} / \mathrm{min} /$ $1.73 \mathrm{~m}^{2}$ or eGFR of $\geq 60 \mathrm{ml} / \mathrm{min} / 1.73 \mathrm{~m}^{2}$ with proteinuria. Proteinuria was defined as a urinary protein level of $1+$ or more (approximately $\geq 30 \mathrm{mg} / \mathrm{dl}$ ) in the dipstick test using a spontaneously and freshly voided urine sample for at least 3 months or more.

Risk factors. To evaluate the clinical risk factors, age, gender, body mass index (BMI), the presence or absence of hypertension, diabetes mellitus, dyslipidemia, cardiovascular disease and pre-ESWL stone position (renal/ureteric) were investigated. Hypertension was defined by i) the administration of antihypertensive agents and/or a history of this disorder; ii) a systolic blood pressure $>40 \mathrm{mmHg}$; or iii) a diastolic blood pressure $>90 \mathrm{mmHg}$. Diabetes mellitus was defined by i) administration of insulin or oral antidiabetic agents or ii) prior diagnosis according to the Report of the Expert Committee on the Diagnosis and Classification of Diabetes Mellitus of the American Diabetes Association (19). Dyslipidemia was defined if the subject exhibited a low-density lipoprotein cholesterol level $>140 \mathrm{mg} / \mathrm{dl}$, triglyceride $>150 \mathrm{mg} /$ $\mathrm{dl}$ and high-density lipoprotein cholesterol $<40 \mathrm{mg} / \mathrm{dl}$, or had received medical treatment for hyperlipidemia. Blood samples were obtained from patients following overnight fasting. Cardiovascular disease was defined as angina pectoris, myocardial infarction, arrhythmia, congestive heart failure, aortic dissection, cerebrovascular disease or peripheral artery disease, including arteriosclerosis obliterans. BMI was calculated by the equation (weight in kilograms)/(square of the height in meters). Based upon the stone position (pre-ESWL), the patients were divided into the renal and ureteric stone groups (subjects with stones in the two positions were included in the ureteric stone group). According to the frequency of the ESWL sessions, the patients were divided into the single and multiple session groups (two times or more). According to the stone size, the patients were divided into the stone length $\geq 10 \mathrm{~mm}$ group and stone length $<10 \mathrm{~mm}$ group.

Statistical analysis. Data were expressed as the percentage or as the mean \pm standard deviation (SD), where appropriate. Differences between the groups were examined using the 
Table II. Factors associated with CKD in patients following successful ESWL.

\begin{tabular}{|c|c|c|c|c|c|}
\hline \multirow[b]{2}{*}{ Variable } & \multirow[b]{2}{*}{ Unit increase } & \multicolumn{2}{|c|}{ Unadjusted } & \multicolumn{2}{|c|}{ Adjusted $^{\mathrm{a}}$} \\
\hline & & Odds ratio $(95 \% \mathrm{CI})$ & P-value & Odds ratio $(95 \% \mathrm{CI})$ & P-value \\
\hline Age & 1 year & $1.067(1.028-1.107)$ & 0.0006 & - & - \\
\hline Gender (males) & & $2.884(1.170-7.107)$ & 0.0214 & - & - \\
\hline Hypertension & & $6.312(1.253-6.211)$ & 0.0424 & $2.011(0.840-4.811)$ & 0.1165 \\
\hline Diabetes mellitus & & $1.024(0.432-2.428)$ & 0.9568 & $0.711(0.276-1.828)$ & 0.4787 \\
\hline Dyslipidemia & & $0.694(0.292-1.650)$ & 0.2910 & $0.854(0.324-2.249)$ & 0.7488 \\
\hline Cardiovascular disease & & $1.806(0.637-5.120)$ & 0.2665 & $1.075(0.334-3.462)$ & 0.9032 \\
\hline Body mass index & $1 \mathrm{~kg} / \mathrm{m}^{2}$ & $1.107(1.005-1.220)$ & 0.0399 & $1.193(1.058-1.345)$ & 0.0039 \\
\hline Stone position (ureteric stone) & & $2.443(1.093-5.461)$ & 0.0295 & $2.612(1.075-6.344)$ & 0.0340 \\
\hline ESWL sessions (multiple) & & $1.105(0.512-2.387)$ & 0.7989 & $0.978(0.419-2.285)$ & 0.9590 \\
\hline Stone size ( $\geq 10 \mathrm{~mm})$ & & $0.696(0.290-1.671)$ & 0.4173 & $0.807(0.310-2.100)$ & 0.6593 \\
\hline
\end{tabular}

Significant factors associated with chronic kidney disease (CKD) were explored among the parameters, such as age, gender (female, 0 ; male,1), hypertension (absent, 0; present, 1), diabetes mellitus (absent, 0; present, 1), dyslipidemia (absent, 0; present, 1), cardiovascular disease (absent, 0 ; present, 1), body mass index, stone position (renal, 0 ; ureteric , 1) and no. of ESWL sessions (single, 0 ; multiple, 1). ${ }^{a}$ Adjusted by age and gender.

Student's t-test or the Mann-Whitney U test. Categorical variables were compared using the Chi-squared test. Logistic regression analysis was performed to assess the effect of variables on the presence of CKD, and dummy variables were used for the presence of hypertension, diabetes mellitus, dyslipidemia and cardiovascular disease (1, presence; 0 , absence), stone position (1, ureteric stone; 0 , renal stone), frequency of ESWL sessions (1, multiple; 0, single) and stone size ( 1 , stone length $\geq 10 \mathrm{~mm} ; 0$, stone length $<10 \mathrm{~mm}$ ) in the logistic regression analysis. $\mathrm{P}<0.05$ was considered to be statistically significant. These tests were performed using the Stat View V Statistical System (SAS Institute Inc., Cary, NC, USA).

\section{Results}

Characteristics of healthy subjects and urolithiasis patients following successful ESWL with and without CKD (Table I). Table I presents the characteristics of the 114 patients following successful ESWL and the 96 healthy control subjects. The prevalence of CKD was significantly higher in the patients following successful ESWL than in the healthy subjects [40 patients $(35.1 \%)$ vs. 9 healthy controls $(9.4 \%)$, $\mathrm{P}<0.0001]$. Among the 114 patients, there was 1 case of CKD Stage 1, 5 cases of Stage 2, 32 cases of Stage 3, 5 cases of Stage 4 and 2 cases of Stage 5. Among the 96 healthy subjects, there were 9 cases of CKD Stage 3 .

The mean age and BMI of the patients with CKD were greater than those of the patients without CKD $(P=0.0002)$. The eGFR of the patients with CKD was significantly lower than that of the patients without CKD $(\mathrm{P}<0.0001)$. Hypertension and ureteric stones were more prevalent in the patients with CKD ( $\mathrm{P}=0.0154$ and $\mathrm{P}=0.0224$, respectively). No significant difference was found in the other factors between the patients with and without CKD.
Factors associated with CKD in patients following successful ESWL (Table II). Univariate logistic regression analysis was performed to examine the correlation between CKD and risk factors among the patients following successful ESWL (Table II). The presence of CKD was significantly associated with older age, male gender, presence of hypertension, ureteric stone (pre-ESWL stone position) and increased BMI. Furthermore, logistic regression analysis following adjustment for age and gender, which were unmodifiable basic clinical factors of the patients, showed that the positive associations between CKD and the presence of a ureteric stone (pre-ESWL stone position) and increased BMI remained significant.

\section{Discussion}

In the present study, we investigated i) the prevalence of CKD and ii) the clinical factors associated with the presence of CKD in patients following successful ESWL. The prevalence of CKD was found to be significantly higher in the patients following successful ESWL than in the healthy subjects. Logistic regression analysis showed that the independent and significant factors associated with the presence of CKD were the presence of ureteric stones (>renal stones) and increased BMI.

Gillen et al (12) reported that among overweight individuals, those subjects with a history of kidney stones exhibited reduced kidney function compared to those without kidney stones. In addition, recent reports (14-16) have shown that kidney stones are a significant and independent risk factor for CKD in the general population. In the present study, the prevalence of $\mathrm{CKD}$ in urolithiasis patients following successful ESWL was found to be $35.1 \%$ (40/114) and was significantly higher compared to that of the healthy subjects (9.4\%; 9/96) (Table I), which was consistent with previous reports (12,14-16), indicating a higher prevalence of CKD in urolithiasis patients compared with healthy populations. 
Although renal function is known to decrease in urolithiasis patients $(12,14-16)$, this is the first report to prove decreased renal function in urolithiasis patients following successful ESWL.

The finding that a history of ESWL was associated with lower eGFR may be attributable to a number of factors (12). Firstly, the stone passage itself causes transient obstruction, and obstruction is a well-established initiator of renal damage. In the present study, renal function was further decreased in the patients with ureteric stones compared to those with renal stones. Since the degree of obstruction was more severe in ureteric stones, despite being transient, renal function may have been more affected in those patients. In addition, stone size did not correlate to renal function in this study, which may have been due to the fact that there was no correlation between the size of the stone and the degree of obstruction. Secondly, ESWL itself may cause renal injury and result in loss of renal function. Although most clinical studies suggest that the initial decline in GFR is capable of improving with time (20), long-term effects are not known and have yet to be elucidated. Although no significant correlation was observed between the frequency of the ESWL sessions and renal function in the present study, a long-term longitudinal study should be conducted to confirm this point. Thirdly, in the more common calcium oxalate stones, it was reported that mineral deposits in the basement membranes of the thin loops of Henle and in the deep medullary interstitium are capable of causing nephron injury and reducing renal function (21).

In the present study, increased BMI was another clinical factor associated with CKD. Previous studies (22-23) have shown that obesity is a risk factor for CKD in the general population, which is consistent with our findings. Since obesity is also a risk factor for urolithiasis, weight control is crucial in preventing CKD and the recurrence of stone formation.

This study has a number of limitations. Firstly, due to the cross-sectional design, our findings do not indicate causality, although this point may be elucidated in longitudinal studies. Secondly, since the stone position was roughly divided into ureteric and renal stones in this study, a more detailed classification is required in future studies. Thirdly, post-ESWL patients were investigated in the present study; however, other treatment methods should also be compared. Fourthly, since detailed information on the stone type was not available for the patients included in this study, it was not included in our examination. However, the association between renal function and the type of stone should be investigated in future studies. Fifthly, as proteinuria was determined only by the dipstick test, we may have underestimated the number of patients who had albuminuria among the CKD Stage 1 and 2 patients.

In conclusion, our findings indicated a high prevalence of CKD among patients following successful ESWL, and that increased BMI and the presence of ureteric stone were factors associated with the presence of CKD.

\section{Acknowledgements}

This study was supported by grants from the Osaka Medical Research Foundation for Incurable Diseases.

\section{References}

1. Foley RN, Murray AM, Li S, et al: Chronic kidney disease and the risk for cardiovascular disease, renal replacement, and death in the United States Medicare population, 1998 to 1999. J Am Soc Nephrol 16: 489-495, 2005.

2. Go AS, Chertow GM, Fan D, McCulloch CE and Hsu CY: Chronic kidney disease and the risks of death, cardiovascular events, and hospitalization. N Engl J Med 351: 1296-1305, 2004.

3. Sarnak MJ, Levey AS, Schoolwerth AC, et al: Kidney disease as a risk factor for development of cardiovascular disease: a statement from the American Heart Association Councils on Kidney in Cardiovascular Disease, High Blood Pressure Research, Clinical Cardiology, and Epidemiology and Prevention. Circulation 108: 2154-2169, 2003.

4. Shlipak MG, Sarnak MJ, Katz R, et al: Cystatin C and the risk of death and cardiovascular events among elderly persons. N Engl J Med 352: 2049-2060, 2005.

5. Coe FL, Parks JH andAsplin JR: The pathogenesis and treatment of kidney stones. N Engl J Med 327: 1141-1152, 1992.

6. Stamatelou KK, Francis ME, Jones CA, Nyberg LM and Curhan GC: Time trends in reported prevalence of kidney stones in the United States: 1976-1994. Kidney Int 63: 1817-1823, 2003.

7. Yoshida $\mathrm{O}$ and Okada Y: Epidemiology of urolithiasis in Japan: a chronological and geographical study. Urol Int 45: 104-111, 1990.

8. Frymoyer PA, Scheinman SJ, Dunham PB, Jones DB, Hueber P and Schroeder ET: X-linked recessive nephrolithiasis with renal failure. N Engl J Med 325: 681-686, 1991.

9. Leumann EP: Primary hyperoxaluria: an important cause of renal failure in infancy. Int J Pediatr Nephrol 6: 13-16, 1985.

10. Worcester EM, Coe FL, Evan AP and Parks JH: Reduced renal function and benefits of treatment in cystinuria vs other forms of nephrolithiasis. BJU Int 97: 1285-1290, 2006.

11. Worcester EM, Parks JH, Evan AP and Coe FL: Renal function in patients with nephrolithiasis. J Urol 176: 600-603, 2006.

12. Gillen DL, Worcester EM and Coe FL: Decreased renal function among adults with a history of nephrolithiasis: a study of NHANES III. Kidney Int 67: 685-690, 2005.

13. Jungers P, Joly D, Barbey F, Choukroun G and Daudon M: ESRD caused by nephrolithiasis: prevalence, mechanisms, and prevention. Am J Kidney Dis 44: 799-805, 2004.

14. Chen N, Wang W, Huang Y, et al: Community-based study on CKD subjects and the associated risk factors. Nephrol Dial Transplant 24: 2117-2123, 2009.

15. Saucier NA, Sinha MK, Liang KV, et al: Risk factors for CKD in persons with kidney stones: a case-control study in Olmsted County, Minnesota. Am J Kidney Dis 55: 61-68, 2010.

16. Rule AD, Bergstralh EJ, Melton LJ, 3rd, Li X, Weaver AL and Lieske JC: Kidney stones and the risk for chronic kidney disease. Clin J Am Soc Nephrol 4: 804-811, 2009.

17. Matsuo S,Imai E,Horio M, et al: Revised equations for estimated GFR from serum creatinine in Japan. Am J Kidney Dis 53: 982-992, 2009.

18. K/DOQI clinical practice guidelines for chronic kidney disease: evaluation, classification, and stratification. Am J Kidney Dis 39: S1-266, 2002.

19. Report of the Expert Committee on the diagnosis and classification of diabetes mellitus. Diabetes Care 20: 1183-1197, 1997.

20. Villanyi KK, Szekely JG, Farkas LM, Javor E and Pusztai C: Short-term changes in renal function after extracorporeal shock wave lithotripsy in children. J Urol 166: 222-224, 2001.

21. Evan AP, Lingeman JE, Coe FL, et al: Randall's plaque of patients with nephrolithiasis begins in basement membranes of thin loops of Henle. J Clin Invest 111: 607-616, 2003.

22. Hsu CY, McCulloch CE, Iribarren C, Darbinian J and Go AS: Body mass index and risk for end-stage renal disease. Ann Intern Med 144: 21-28, 2006.

23. Yamagata K, Ishida K, Sairenchi T, et al: Risk factors for chronic kidney disease in a community-based population: a 10-year follow-up study. Kidney Int 71: 159-166, 2007. 